Egypt. J. Aquat. BioL \& Fish. Vol. 10, No. 1:55 - 71 (2006) ISSN JUO 6131

\title{
PARASITOLOGICAL AND HISTOPATHOLOGICAL STUDIES ON THE GRASS CARP CTENOPHARYNGODONIDELLA INFESTED WITH TRICHODINA ACUTA WITH SPECIAL EMPHASIS ON ITS CONTROL
}

\section{Mohamed Abdel-Meguid}

Environment and Climate Research Institute, National Water Research Center, El Kanater, Kalubyia, Egypt

Key Words: Ctenopharyngodon idella, Trichodina acuta, treatment

\begin{abstract}
A $\mathrm{n}$ experimental study was conducted to reveal the morphological Astructure of the ciliate ectoparasite Trichodina acuta on the grass carp Ctenopharyngodon idella, to study the histopathological changes in these infested fish, and to assess potential therapeutic agents. It was found that in the fish fry weighing $0,001 \mathrm{~g}$., the parasite was found on the skin but in the fmgeriing weighing 10 grams it infested on both the skin and the gill filaments. The biometrical data showed that the morphological structure of the protozoan parasite was highly dependent its location on the skin or the gill filaments and on the size of the host fish. Although, larger fish showed detrimental effects due to parasitic infestation, small fish were more susceptible. Histopathological examination of the skin and the gills of infested large fish revealed no apparent microscopic lesions. However, $T$. acuta invaded the skin of early stages of fish and caused epithelial hyperplasia and extensive mucus secretions. It was found that formalin, malachite green and potassium permanganate were therapeutic and prophylactic against this protozoan parasite.
\end{abstract}

